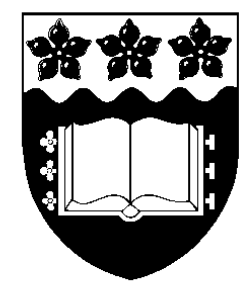

University of Wollongong

Economics Working Paper Series 2004

http://www.uow.edu.au/commerce/econ/wpapers.html

Lemons on the Web: A Signalling Approach to the Problem of Trust in Internet Commerce

Boon-Chye Lee

Lawrence Ang

and

Chris Dubelaar

WP 04-10

July 2004 


\title{
Lemons on the Web: A Signalling Approach to the Problem of TRUST IN INTERNET COMMERCE*
}

\author{
by \\ Boon-Chye Lee \\ School of Economics and Information Systems \\ University of Wollongong \\ Wollongong, NSW 2522 AUSTRALIA \\ Tel: +61 $24221-4023$ \\ Fax: +61 2 4221-6275 \\ Email: boon@uow.edu.au \\ Lawrence Ang \\ Macquarie Graduate School of Management \\ Macquarie University \\ NSW 2109 AUSTRALIA \\ and \\ Chris Dubelaar \\ Department of Marketing \\ Monash University \\ Caulfield East, VIC 3145 AUSTRALIA
}

\footnotetext{
* The authors gratefully acknowledge helpful comments by Amnon Levy, John Powell and John Rodgers.
} 


\title{
Lemons on the Web: A Signalling Approach to the Problem of TruST IN INTERNET COMMERCE
}

\begin{abstract}
Asymmetric information is at the heart of situations involving trust. In the case of B2C Internet commerce, the information asymmetry typically relates to the difficulty that consumers have of distinguishing between "trustworthy" and "untrustworthy" Web merchants. The impasse can be resolved by the use of signals by trustworthy Web merchants to differentiate themselves from untrustworthy ones. Using an experimental design where subjects are exposed to a series of purchase choices, we investigate three possible signals, an unconditional money-back guarantee, branding, and privacy statement, and test their efficacy. Our empirical results confirm the predictions suggested by signalling theory.
\end{abstract}

PsycINFO classification: 3900

JEL classification: D82, M21

Keywords: trust (social behaviour); consumer behaviour

\section{Introduction}

The problem of lack of trust on the part of Internet users regarding commercial web sites is well known by now (see, for example, Cranor et al., 1999; and Hoffman et al., 1999). The crux of the problem is imperfect or asymmetric information (Akerlof, 1970; Ben-Ner \& Putterman, 2003). A situation is characterised by imperfect information when economic agents do not have full information about a product and/or its market. A special case of imperfect information, asymmetric 
information, occurs when one side to a transaction has better information than the other about relevant aspects of the transaction.

In the context of business-to-consumer ("B2C") Internet commerce, the information asymmetry typically relates to the difficulty that consumers have of distinguishing between "trustworthy" and "untrustworthy" Web merchants. Asymmetric information can prevent consumers from making an accurate assessment of the terms on which they are transacting and consequently deter them from transacting at all because they are wary of opportunistic behaviour by the other party. It can therefore be the cause of a potential market not developing at all, or an existing market disappearing altogether. Akerlof's (1970) seminal paper analysed the used car market, but other examples of markets characterised by asymmetric information include insurance markets (Rothschild \& Stiglitz, 1976), credit markets (Stiglitz \& Weiss, 1981), and generally retail markets for goods or services of unknown quality. The problems arising in these markets are exacerbated in Internet commerce by the relatively unfamiliar and impersonal nature of the Web, where the lack of opportunities for face-to-face interactions reduces people's ability to detect deception (Ben-Ner \& Putterman, 2003).

In the typical scenario in which trust is required, the act of trusting exposes the trustor to the possibility of an adverse outcome. That is, it entails taking a risk that will not be taken unless the risk is judged to be acceptably "low" (i.e., the trustor is sufficiently confident of the other's intentions). But evaluating risk requires information or knowledge about the other party so that an informed judgment can be made. In settings with asymmetric information, market mechanisms may be developed that would at least partially alleviate the information deficit. An important example of such a mechanism is market signalling (Spence, 1973, 1974). This is the 
approach we adopt in our paper. If Web merchants can be characterised as either trustworthy or untrustworthy and potential consumers cannot readily tell them apart, trustworthy merchants can attempt to differentiate themselves from untrustworthy ones by taking actions which are less costly to them than they are to the untrustworthy merchants. These actions serve as "signals" to the market. Market signals play an important and recognised role in product markets where quality uncertainty is a problem (Kirmani \& Rao, 2000), with manufacturers commonly offering product warranties as signals of product reliability (Price \& Dawar, 2002).

An important aspect of our paper is the efficacy of different signals used by Web merchants to increase consumer trust. The use of signals such as warranties and brands in the physical world is well documented and has been the subject of much research (see, for example, Wiener, 1985; Boulding \& Kirmani, 1993; and Price \& Dawar, 2002). Using an experimental design where subjects are exposed to a series of purchase choices, we investigate how effectively these signals operate, and whether they function in the same way for a Web retailer versus a "bricks and mortar" retailer.

The paper is structured as follows. In Section 2, we discuss some relevant concepts relating to trust. In Section 3, we outline our approach based on signalling as a means of allowing trustworthy Internet retailers to communicate their true characteristics to potential customers. The research methodology is detailed in Section 4, and the results are presented in Section 5.

\section{Trust Concepts}

The literature on trust is extensive and multi-faceted, spanning as it does a range of disciplines. However, in spite of the diversity of approaches, there is a remarkable degree of consistency in the conceptions of trust across disciplines. As 
Rousseau et al. (1998: 394) note in their introduction to the collection of papers in the Academy of Management Review's special issue on trust, "[r]egardless of the underlying discipline of the authors... confident expectations and a willingness to be vulnerable are critical components of all definitions of trust reflected in the articles" (italics added). These two elements constitute the core aspects of the act of trust identified by the literature.

Trustworthiness may be distinguished from trust by identifying the former as an attribute or characteristic of the trusted party (Mayer et al., 1995). Commonly understood notions of trust involve, among other things, the fact that trust is vested in some dimension or attribute of a person or thing, implying that a person may be judged to be trustworthy in some respects but not in others. Webster's Dictionary, for example, defines trust as "assured reliance on some person or thing: a confident dependence on the character, ability, strength, or truth of someone or something." This line of reasoning has resulted in studies which have attempted to identify the key dimensions or aspects of a person that may be found to be trustworthy - that is, the key dimensions of trustworthiness. A frequently used classification is that of Mayer et al. (1995), who identify three dimensions which, they argue, "explain a major portion of trustworthiness.” They term these Ability, Benevolence, and Integrity.

\section{Ability}

Ability, also known as "competence" (Barber, 1983), refers to the "skills, competencies, and characteristics that enable a party to have influence within some specific domain" (Mayer et al., 1995: 717). Trust relationships in some contexts, particularly commercial or professional ones, are often based on the technical or professional competence of the trusted party (Barber, 1983). It is also encountered in 
retail transactions when we rely on the claims made by the retailer that the product he is selling will perform certain functions (and perform them reliably). This aspect of trustworthiness tends to be functional in nature, and assumes relatively greater importance in goal-oriented relationships such as those in commercial and professional contexts where the prime purpose of the relationship is consummating a transaction or getting a job done.

\section{Benevolence}

Mayer et al. (1995) define Benevolence as "the extent to which a trustee is believed to want to do good to the trustor, aside from an egocentric profit motive." Although Benevolence arises most commonly in the context of interpersonal relationships, something resembling it occurs in commercial contexts as well (Phelps, 1975). For example, commercial enterprises will sometimes attempt to demonstrate their goodwill or corporate sense of responsibility either to their customers or to society in general by committing themselves to policies which would seem to go beyond the call of duty in carrying out transactions with their customers, possibly even in violation of a strict profit motive. Examples of this include a green or environmentally friendly policy, and acts of corporate philanthropy.

\section{Integrity}

According to Mayer et al. (1995: 719), "the relationship between integrity and trust involves the trustor's perception that the trustee adheres to a set of principles that the trustor finds acceptable." In commercial contexts the integrity of the merchant relates most closely to the principle that business practices should be fair and equitable to the customer, especially if an explicit promise has been made to them. For instance, if a 
product breaks down within the warranty period, Integrity requires that the problems be rectified as specified in the warranty agreement. A privacy policy promising to preserve the confidentiality of their customers' personal information may also be regarded as a signal of Integrity because it conforms to customers' views of what constitutes acceptable behaviour regarding their personal information.

\section{Asymmetric Information and Trust}

\subsection{Signals of Trustworthiness}

A signal is an action taken by the better-informed party in a setting of asymmetric information to communicate its true characteristics in a credible fashion to the less-informed party. Where potential customers are faced with two broad "types" of Web merchants, trustworthy or untrustworthy, the effectiveness of the signal depends on its ability to resolve the customer's classification problem (Boulding \& Kirmani, 1993). We now consider three signals of trustworthiness that may be used by a Web merchant: the use of a Brand; the presence of a Privacy Policy on the merchant's Web site; and a 30-day unconditional Money-Back Guarantee.

\section{Brand}

Branding is a well-known strategy which, like a warranty, can potentially signal both product reliability and performance, depending on the retailer's positioning (Price \& Dawar, 2002). Both product reliability and performance are elements of Ability. However, the use of a brand assumes a reputation of sorts. Branding is not a very effective strategy if the brand has little or no recognition among consumers. The problem facing many new or start-up Web merchants is that they lack a reputation or anything of a profile. One strategy around this difficulty is that of "reputation 
transfer" (Stewart, 1999): for example, by the Web merchant acting purely as an intermediary in selling a product under a well-known brand (Swait et al., 1993; Erdem \& Keane, 1996). Tan (1999) found that if the purchase amount at risk is relatively high (e.g., an inkjet printer), having an established brand is very effective in reducing the perceived risk on the Internet.

\section{Privacy Policy}

The presence of a Privacy Policy that claims to honour the confidentiality of personal information provided in the course of a sale seeks to address one of the key concerns of web users (Culnan, 2000). Surveys of Web users (e.g., Department of Commerce, 1998; Hoffman et al., 1999) typically reveal a high level of concern regarding the confidentiality of personal information. As argued earlier, a Privacy Policy can act as a signal of the retailer's Integrity because it conforms to customers' views of what constitutes acceptable behaviour regarding their personal information.

\section{Unconditional Money-Back Guarantee (MBG)}

An unconditional MBG is an example of a signal that may convey information on more than one dimension of trustworthiness. An unconditional MBG means that if a customer is dissatisfied for whatever reason, no matter how trivial, he can have his money refunded. In direct marketing, this promise usually extends for a certain period (e.g., 30 days) after the purchase. Allowing a "cooling off period" is thought to be fair and equitable since the customer does not have the benefit of physically examining the product before purchase, and may be unduly influenced to buy on impulse. Because of this, offering an unconditional MBG may constitute a signal of the Integrity of the retailer, who is seen to be fair. But it may also convey information 
about the retailer's Benevolence if offering an unconditional MBG is not the norm in the industry, allowing the retailer to be perceived as exceeding its expected commercial obligations to the customer (and, hence, "Benevolent"). In addition, the fact that an unconditional MBG has been offered could also constitute a signal of the seller's confidence in its product and hence of the "Ability" aspect of the seller's trustworthiness.

\subsection{Signalling Equilibria and Signal Credibility}

The situation described in the foregoing sections may be characterised as a signalling game (Bacharach \& Gambetta, 2002). The credibility of signals is an important consideration in the analysis of signalling games: if anyone can send a signal, it loses its potency. The game theoretic literature offers useful insights into the nature of the equilibria in signalling games (Spence, 1973; Bacharach \& Gambetta, 2002), and these have direct implications for the credibility of the signals involved.

Three kinds of equilibrium are distinguished. First, a separating equilibrium exists when there is at least one signal which is cheap enough, relative to the benefit, for truthful signallers to send but which is too costly, relative to the benefit, for untruthful signallers to send. Expressed in the context of trustworthy/untrustworthy Web retailers: assuming that the benefits of sending the signal (making a sale), denoted $B$, are the same for both types of retailers, and denoting the cost of the signal to a trustworthy retailer by $S_{T}$ and the cost of the signal to an untrustworthy retailer by $S_{U}$ the following cost relationships must hold for a separating equilibrium:

$$
B-S_{T}>0 \text { and } B-S_{U}<0
$$

Moreover, these facts must be apparent to everyone, signallers as well as receivers of the signals. The equilibrium that emerges is known as a "separating" 
equilibrium because the signal distinguishes perfectly between the trustworthy and the untrustworthy retailers - that is, it is highly credible. Sending the signal unequivocally conveys the message that the retailer is trustworthy; and, under these conditions, not doing so unequivocally conveys the opposite message. The reason is that it does not pay an untrustworthy retailer to mimic a trustworthy one by sending the signal; since all untrustworthy retailers will not send the signal, any trustworthy retailer, not wishing to be mistaken for an untrustworthy one, will have an incentive to send it. This is an equilibrium because, once the retailers of both types have chosen their strategies (to send or not to send the signal) they have no incentive to change them.

Second, there are semi-separating equilibria (Bacharach \& Gambetta, 2002). These are "dirtier" in the sense that in a semi-separating equilibrium all the trustworthy retailers will send the signal concerned, but so also will a proportion of untrustworthy ones. The latter do so in order to "mimic" the trustworthy retailers. In the case of semi-separating equilibria, the cost relationships are:

$$
B-S_{T}>0 \text { and } B-S_{U}=0
$$

Finally, pooling equilibria are those where both trustworthy and untrustworthy retailers send the same signal, so that they cannot be distinguished from one another. The signal is therefore uninformative.

What produces these different equilibria is the structure of costs and benefits for the two types of retailers. The cost criterion can operate in two ways. The cost can be incurred directly, in the process of acquiring and/or sending the signal. For example, in Spence's (1973) analysis of the job market and the use of higher educational credentials as signals, because high-productivity workers possess more ability than low-productivity workers, they can acquire these credentials at lower cost. In this case, the cost is incurred in the process of acquiring the signal. 
The cost criterion can also operate indirectly, by way of a "bonding" component to the signal, or a penalty that is incurred for false signalling (Ippolito, 1990) - that is, it is incurred after the signal is sent, and then only if the signal is a false one. This is more common in commercial transactions, particularly for experience goods, where the truth of a signal is revealed only after the transaction has been completed. The penalty could take the form of loss of income or reputation. Signal credibility in this case arises from perceptions about the size and likelihood of the penalty (Price \& Dawar, 2002). Opportunities for deception by untrustworthy retailers are present if the penalty is insignificant, or if it is high but the probability that a false signaller will incur it is low, as in the case of a "fly-by-night" operator.

Thus, if the expected penalty (its size $\times$ likelihood) for false signalling is "high", the equilibrium will be a separating one. If the expected penalty is "low", the equilibrium will be a pooling one; and if the expected penalty for false signalling is "intermediate", the equilibrium will be a semi-separating one. The question is whether, among the signals available to Web retailers, the conditions for a separating equilibrium apply to any of them.

In the case of an unconditional MBG, in order for it to be effective as a signal of product quality or reliability or generally trustworthiness, it must be less costly for the retailer of the high quality product to offer it than for the retailer of the low quality product - for example, because of the lower rate of defects on the high quality product. The signal would carry considerable credibility if there is a formal institutional mechanism in place (e.g., a small claims court) to enforce the MBG. In the context of transactions conducted across national borders and possibly beyond the reach of law enforcement mechanisms, how effectively the signal functions is an 
interesting question. Similar considerations are relevant in the case of Brand and Privacy Policy as signals of trustworthiness.

\section{Testing Signals of Trustworthiness in Internet Commerce}

For our empirical study, we envisage the following static scenario in the context of business-to-consumer (B2C) Internet commerce: an individual is placed in a situation where they are looking to purchase a computer, a pair of jeans, a pair of shoes, or a watch; they are asked to choose between a "bricks-and-mortar" (B\&M) store and a Web site at which to make their purchase - or to make no purchase at all. The parties have not previously interacted and the interaction is on a one-off basis, so there is no opportunity for a relationship or reputation to develop. This scenario contrasts with the more complex dynamic case in which a relationship between the consumer and merchant develops or evolves over time.

\subsection{Contextual Factors}

In addition to the three signals of trustworthiness (MBG, Brand, and Privacy Policy) discussed earlier, certain contextual factors can also affect the likelihood of an online purchase. These include the product category, the time between ordering and receipt (delivery time), and any price discounts offered.

\section{Product Category}

Not all products are equally amenable to be sold on the Internet. A number of products, including music, computer software and equipment, and books, comprise the bulk of retail goods sold online (OECD, 2000), while jeans, shoes and perfumes tend to be avoided (Ang et al., 2001; Chiang \& Dholakia, 2003). One reason may be 
the difference between search and experience goods (Nelson, 1970). Search goods like books, whose "dominant" attributes are known prior to purchase, may be more amenable to be sold online because consumers have more information about relevant aspects of the goods prior to purchase (Chiang \& Dholakia, 2003). By contrast, experience goods like perfume need to be tried before consumers understand them fully. On the other hand, online merchants will often provide information on their products regardless of whether they are search or experience goods. Indeed, Klein (1988) argued that the traditional distinction of search versus experience goods may be blurred on the Internet because, with (ever more powerful) virtual technologies, all goods can (eventually) be experienced.

A different perspective from the notion of "information search" is that of product heterogeneity (Li \& Gery, 2000), that is, the idea that the relevant aspects of some product categories can be specified or described more fully than others. Our choice of product categories (computers, wristwatches, jeans and shoes) is intended to highlight the contrast between goods that are amenable to standardised descriptions and those that are not. In this regard, computers and computer parts are highly standardised: a computer monitor, for example, can be specified to a very precise level of detail, leaving little room for uncertainty and specification errors. This is roughly true also of wristwatches. Towards the other end of the "standardised specifiability" spectrum, shoes and jeans belong to a category of products that are to some extent specifiable by size but are much less amenable to standardised specification (e.g., due to variations in fit, size and colour), so that product description may be more difficult. Furthermore, because tactility (touch and feel) is an important selection criterion, the probability of purchase error is higher if they are not tried on 
before purchase. Accordingly, most people will prefer to try on a pair of shoes or jeans before purchase to test for fit, comfort and "how they look on me".

\section{Delivery Time}

Whilst the Internet is said to herald a new level of convenience for consumer shopping (Donthu \& Garcia, 1999), it also suffers from the disadvantage of delayed product delivery (Pavitt, 1997). Furthermore, the consumer is often charged for delivery, and in some cases (e.g., grocery goods), has to be home at a certain time to receive the goods. Such inconveniences do not occur with traditional Bricks and Mortar (B\&M) shopping - if a consumer needs a product immediately, traditional B\&M may be the only option. Besides an immediate need, the reluctance to wait may be related to a desire for instant gratification (Rosen \& Howard, 2000).

In our study, we manipulated delivery time as either fast (within 24 hours for jeans, sports shoes and wrist watch; 1 week for personal computer) or slow (within 1 week for jeans, sports shoes and wrist watch; 1 month for personal computer). These times were chosen to reflect the range of possibilities for B\&M and online shopping.

\section{Discount}

For many people, a major motive for shopping on the Internet is the promise of cheaper prices (Reed, 1999). Furthermore, on the Internet price comparisons are easy to carry out using shopping bots or agents and price comparison sites. Shern \& Crawford (1999) found that consumers often use the Internet as a tool for information research, including information about prices, prior to making their purchases. The Internet also renders the cost of goods more transparent, making it even more difficult for manufacturers to charge a premium (Sinha, 2000). However, offering price 
discounts on the Internet may not be equally attractive for all products. Chiang (2001) found that for a given percentage discount in the case of computers, the higher the price, the more likely people are to buy on the Internet. But this was not found for other product categories like books or perfume (Chiang \& Dholakia, 2003).

In our study, we manipulate price discount (versus regular price) by directly telling people the percentage discount (i.e., 20\%) instead of giving them the final discounted price of the product. Since consumers interpret the price based on assimilation and contrast (Zeithaml, 1988; Sherif et al., 1965), it is thought that giving them the size of discount would create a greater contrast effect. To make it more realistic, the regular price of the products was also given at the beginning of the study, but during the (choice) experiment, only the size of the discount was mentioned.

\subsection{Hypotheses}

Based on our discussion, a number of hypotheses suggest themselves. Our basic postulate is that a signal that increases the perception of the merchant's trustworthiness will, other things equal, increase the probability of a purchase from that merchant.

\section{Brand}

As discussed, the use of a branded product is a common strategy to signal Ability. Moreover, because of the uncertainty surrounding Web transactions compared to physical-world ones, we postulate that signals of trustworthiness are more important on the Web than in the physical world. This suggests the following hypotheses:

H1a: Branded products are more likely to be purchased than non-Branded products. 
H1b: The effect of Brand will be greater for Web merchants than for Store merchants.

\section{Privacy Policy}

We argued earlier that the presence of a Privacy Policy is a signal of Integrity and serves to assure customers that the company will not misuse their personal information. This suggests the following hypothesis:

H2: The presence of a Privacy Policy increases the probability of a purchase.

\section{Unconditional Money-Back Guarantee (MBG)}

As discussed, an unconditional MBG can be a signal of more than one dimension of trustworthiness. If credible, it would be especially important for Web transactions since consumers do not have a chance to examine the product closely before buying. Hence the following hypotheses:

H3a: Offering an unconditional MBG increases the probability of a purchase.

H3b: Offering an unconditional MBG increases the probability of a purchase to a greater degree for a Web merchant than for a Store merchant.

\subsection{Method}

In order to extract the effects of each of the signals on trust, we make the assumption that trust is a necessary but not sufficient condition for purchase. We then propose that if someone is willing to purchase something, they have therefore demonstrated trust. To operationalise this, we created a series of choice experiments 
that asked our respondents to choose one of three alternatives in each of a series of choice tasks. In these choice tasks we manipulated both the signals (Brand of the product, existence of a Privacy statement, and MBG) as well as the context factors (delivery time and price) in each of four product categories (shoes, watches, computers, and jeans). Our design was a main effects foldover resulting in 24 choice tasks per product. Each respondent was asked to respond to choice tasks on two separate products. Products were paired in each of six possible configurations (four choose two) and each respondent also was asked to respond to a series of manipulation check and demographic questions at the end of the instrument.

\subsubsection{Choice tasks}

The choice task was presented using a table and icons that were explained comprehensively at the outset. As our preliminary research had indicated that nobody would purchase online on an insecure site, all online sales were stated to have the latest in security installed. Each of the attributes was explained on the front page of the instrument and each attribute had icons associated with high and low (or present versus absent) conditions. A sample choice task is shown below. 


\begin{tabular}{|c|c|c|c|c|c|c|c|c|}
\hline $\begin{array}{l}\underline{\text { Choice }} \\
\underline{\text { Set } 9}\end{array}$ & Product & Brand & $\begin{array}{c}\text { Money } \\
\text { Back } \\
\text { Guarantee }\end{array}$ & $\begin{array}{c}\text { Delivery } \\
\text { Time }\end{array}$ & Price Level & $\begin{array}{l}\text { Where } \\
\text { Sold }\end{array}$ & $\begin{array}{c}\text { Privacy } \\
\text { Statement }\end{array}$ & $\begin{array}{c}\text { Tick One } \\
\text { Only }\end{array}$ \\
\hline $\begin{array}{c}\text { Scenario } \\
1\end{array}$ & & LEvis & & & & पII & & \\
\hline $\begin{array}{c}\text { Scenario } \\
2\end{array}$ & $M$ & exinz & & & \begin{tabular}{|l|}
$20 \%$ \\
OFF
\end{tabular} & WwW & PRIVACY & \\
\hline $\begin{array}{c}\text { Scenario } \\
3\end{array}$ & \multicolumn{7}{|c|}{ Neither of the above scenarios interests me } & \\
\hline
\end{tabular}

The order of the first two choices (in a retail shop versus online) was randomised throughout the six instruments, while the third choice (none of the above) remained as the third choice.

To avoid inference effects, the base prices of products within a category (branded or otherwise) were the same, and it was explained that these products were essentially identical. Also, the base warranty (as opposed to MBG) was stated as being identical for all products. Specifically, in the category of computers, both the branded and unbranded versions came with the same 12-month replacement warranty in the event of a defect in the product. This is distinct from the MBG in which the purchase price is refunded regardless of the reason for returning the goods.

\subsubsection{Respondent Recruiting}

Respondents were recruited from undergraduate and postgraduate classes at three universities in five cities, three in Australia, and two in Asia. Respondents were asked to complete the instrument at the end of a class and return the instrument before 
leaving the room. Respondents were not required to do the survey, but were asked to participate by their lecturers. No inducement was given for participation. All responses were anonymous.

\section{Results and Discussion}

\subsection{Results}

Response rates were approximately $40 \%$ with 132 useable responses from 325 instruments handed out. Of the respondents, 57\% (76) were male, and 43\% (56) were female. $56 \%$ were under 25 years old, while $26 \%$ were between 26 and 35 years old and the remaining $18 \%$ were over 35 . Of our respondents, $48 \%$ had bought something online in the previous two years. From the 132 respondents we received 6749 choices, of which 1526 were for shoes, 1922 were for watches, 1465 were for computers, and 1836 were for jeans. Manipulation checks showed that our brand and non-brand names were effective with the every real brand being recognised by at least $95 \%$ of all respondents while, of the non-brands, our invented brand for computers (Compstar) was the worst performer with $23 \%$ claiming recognition, while the rest were $5 \%$ (Jeenz), and 16\% each for watches and shoes (Timeo and Sportz respectively).

The overall model including all choices was estimated using Limdep NLogit 3.0. We assessed the alternative specific constants (ASC) and the unique utility functions for each of the alternatives. The ASC is the estimated base utility for each of the alternatives (WWW and Shop) compared to the third, baseline alternative (none of the above). The unique utility functions reveal the relative effects of attributes on utility for the each of the two alternatives. The model results are presented in Table 1. The first column shows the results for the model ignoring product, and the subsequent four columns show the results for each of the products taken separately. 


\section{Insert Table 1 about here}

The results show that for each of the five models, Brand is significant in both channels, thus supporting H1a. Further, while in all cases the coefficient is larger for Brand on the Internet than for Brand in a Store, a chi-square constraint test (forcing the two coefficients to be equal and then re-estimating the model) shows that these differences are not significant. Thus, hypothesis H1b is not supported. This is the case for all models at all levels (full model with all responses and models representing only one product at a time - with the $p$ values ranging from 0.12 to 0.67 ).

Hypothesis 2 suggested that the presence of a Privacy policy signal would increase the probability of a purchase. This is seen through the positive, significant coefficients for Privacy in the model, thus supporting H2.

Hypothesis 3a is also supported, with the MBG having a significant, positive coefficient. Further, the coefficients for MBG in each of the two channels differ, with the coefficient for WWW always being larger than that for Store. This difference is significant, but only for the model of all products combined ( $p$ value 0.019 ). None of the individual product models showed a significant difference when the values of the coefficient for MBG were constrained to be equal ( $p$ values ranged from 0.088 to 0.938), thus providing only limited support for hypothesis H3b.

The ASCs for Store are only sometimes significantly different from zero. That is, people were just about as likely to choose to buy in a Store as to choose "none of the above" in all cases except for watches and computers. As the ASCs for WWW were always significantly different from zero, and always negative, this means that there are clear differences in all cases except computers (when both ASCs are on the same side of zero and both are significant). Even in this case, the chi-square test of 
constraining the two constants to be equal shows that the difference between the constants is highly significant $(p<0.0001)$.

\subsection{Discussion}

Our results indicate that Web merchants can affect the purchase intentions of potential customers by conveying information about the three aspects of trustworthiness through the use of signals. We showed that each of the aspects of trustworthiness operates in several different contexts, and signals provide additional information that potential Web buyers look for to help them decide whether to purchase online. We therefore believe that trust is developed as a result of signals sent and received between the two sides to a potential transaction. We should note, however, that for most of the products it was a case of "whatever the Web can do, the store can do better", as only for watches and computers could our respondents be shown to have a slight preference for buying on the Internet versus buying at a store when all the signals are activated.

The way our model was built, the presence or absence of a stimulus (Brand, MBG, Privacy statement, or a Discount) were all coded as equivalent in the analysis. That is, introducing a known Brand is accorded the same "value" as introducing a MBG. However, the scales for these two things are really unknown, and thus caution needs to be exercised when comparing coefficients. Thus, we cannot say that, in the case of the full model for example, Delivery Times have to be cut by half again in order to equate to introducing a Brand. These values do not compare directly. 


\section{Brand}

Overall, the results for Brand are as expected: a well-known and reputable brand sends a strong signal about Ability (the ability of the product to perform as claimed). However, the fact that Brand is significant in both channels, but not significantly more so in the online channel, was somewhat surprising. Our expectation was that, given the relative paucity of information online compared to the physical world, Brand would have had more of an information effect in the online channel than the offline channel and thus should have had a significantly larger coefficient. The result implies that Brands are important, but that people perceive the signals Brands send in a similar way irrespective of the medium through which the product is sold.

\section{Privacy}

Although the results relating to Privacy support our hypothesis that the presence of a Privacy Policy increases the probability of a purchase, the degree of significance of the coefficient is surprising from one perspective. Since any Web retailer can inexpensively insert a statement about a "Privacy Policy" on its Web site, it appears that the direct costs of doing so are "low". If we consider the other kind of cost - viz., the penalty for false signalling in the form of lost future sales - this would appear to be low as well: consumers would have difficulty monitoring the retailer's compliance with its Privacy policy, so the probability of detecting false signalling is low. This leads us to expect that Privacy as a signal of one aspect of the retailer's trustworthiness will produce at best a semi-separating equilibrium: trustworthy retailers will send the signal but so will some untrustworthy retailers, in an attempt to mimic the trustworthy ones. In this case, we would expect some confidence to be placed in the signal, but also some allowance for the possibility of false signalling. 
The strength of the result indicates that our respondents placed greater confidence in this signal than might be expected.

Two main conclusions may be drawn. First, the significance of the Privacy coefficient indicates that the signal communicates useful information about the Web retailer's trustworthiness. This helps to explain why most Web sites (from casual observation) that have Privacy policies do not take the extra step of having those policies certified by a trusted third party like TRUSTe or BBB Online and thus acquire additional credibility.

Second, it is clear that Privacy does not act as a hygiene factor. If it had been a hygiene factor, Privacy would have dominated the other variables and no choice would have been made for an online purchase unless and until Privacy was present. This was not the case. The result is consistent with the findings of Spiekermann et al. (2001) that people's expressed concerns regarding privacy are often not matched by their revealed preferences. It is also consistent with the argument that while control over the use of private information matters to people, there are different degrees of "information sensitivity" and people may be willing to trade less sensitive information in exchange for some form of compensation (Sheehan \& Hoy, 2000; Milne \& Gordon, 1993) such as convenience and price.

\section{Money-Back Guarantee}

The MBG result indicates that this signal works better online than it does in a store. The finding that the store and online coefficients for MBG are significantly different from each other only for the model taken as a whole, however, may reflect the fact that the MBG signal may be subject to credibility problems. In particular, a Web customer located in a different country from the Web retailer may have reason to 
question the enforceability of the promise embodied in the MBG. Taken in conjunction with the fact that the MBG coefficients across the five models are all highly significant, this suggests that, as is also likely to be the case with Privacy, the equilibrium is a semi-separating one.

It also indicates that the signal conveys useful information about the retailer's confidence in its product and possibly other aspects of its trustworthiness, as we argued earlier. Again, as in the case of Privacy, although there are avenues available for a retailer to enhance the credibility of this particular signal if it so wishes (for example, by having its MBG guaranteed in turn by an internationally reputable insurance company such as Lloyds of London, as some Web businesses have done) the fact that an MBG is offered at all would appear to convey a significant amount of information to potential consumers.

\section{Conclusions}

We suggest that the Web retailer's problem of communicating information about its trustworthiness can be understood as a signalling-based phenomenon. Our experiment used three signals that represented three commonly identified aspects of trust (Ability, Benevolence, and Integrity) and showed that changes in these three signals cause changes in purchase behaviour in a choice modelling experiment. From this we conclude that trustworthiness can be signalled. 


\section{References}

Akerlof, G. (1970). The Market for Lemons. Quarterly Journal of Economics, 84(3), 488-500.

Ang, L., C. Dubelaar \& B.C. Lee (2001). To Trust or Not to Trust? A Model of Internet Trust From the Customer's Point of View. Proceedings, $14^{\text {th }}$ Bled Electronic Commerce Conference, Bled, Slovenia, June.

Bacharach, M. \& D. Gambetta (2001). Trust in Signs. In K.S. Cook (ed.), Trust in Society, New York: Russell Sage Foundation, 148-184.

Barber, B. (1983). The Logic and Limits of Trust. New Brunswick, NJ: Rutgers University Press.

Ben-Ner, A. \& L. Putterman (2003). Trust in the New Economy. In D.C. Jones (ed.), New Economy Handbook, Academic Press, 1067-1095.

Boulding, W. \& A. Kirmani (1993). A Consumer-Side Experimental Examination of Signaling Theory: Do Consumers Perceive Warranties as Signals of Quality? Journal of Consumer Research, 20(1), 111-123.

Chiang, K.P. (2001). Effects of Price, Product Type and Convenience on Consumer Intention to Shop Online. In R. Krishnan and M. Viswanathan (eds.), Proceedings of AMA Winter Educator's Conference, Vol. 12.

Chiang, K.P. \& Dholakia, R.R. (2003). Factors Driving Consumer Intention to Shop Online: An Empirical Investigation. Journal of Consumer Psychology, 13 (1\&2), $177-183$

Cranor, L.F., J. Reagle \& M.S. Ackerman (1999). Beyond Concern: Understanding Net Users' Attitudes About Online Privacy. AT\&T Labs-Research Technical Report TR 99.4.3, 14 April. 
Culnan, M.J. (2000). Protecting Privacy Online: Is Self-Regulation Working? Journal of Public Policy and Marketing, 19(1), 20-26.

Department of Commerce (1998). The Emerging Digital Economy. Secretariat on Electronic Commerce, U.S. Department of Commerce.

Donthu, N. \& A. Garcia (1999). The Internet Shopper. Journal of Advertising Research, Vol. 39(3), 52-58.

Dubelaar, C., C. Jevons \& L. Parker (2003). Personal Information Privacy and Shopping Behaviour on the Internet. Journal of Asia Pacific Marketing, 2(1), 6574.

Erdem, T. \& M. Keene (1996). Decision Making Under Uncertainty: Capturing Dynamic Brand Choice Processes in Turbulent Consumer Goods Markets. Marketing Science, Vol. 15, Winter, 1-20.

Hoffman, D.L., T.P. Novak \& M. Peralta (1999). Building Consumer Trust Online. Communications of the ACM, 42 (4), 80-85.

Ippolito, P.M. (1990). Bonding and Nonbonding Signals of Product Quality. Journal of Business, 63 (1), 41-60.

Kirmani, A. \& A.R. Rao (2000). No Pain, No Gain: A Critical Review of the Literature on Signaling Unobservable Product Quality. Journal of Marketing, 64 (2), 66-79.

Klein, L.R. (1988). Evaluating the Potential of Interactive Media Through a New Lens: Search versus Experience Goods. Journal of Business Research, 41, 195203.

Li, Z.G. \& N. Gery (2000). E-tailing - For All Products? Business Horizons, 43(6), $49-54$. 
Mayer, R.C., J.H. Davis \& F.D. Schoorman (1995). An Integrative Model of Organizational Trust. Academy of Management Review, 20(3), 709-734.

Milne, G.R. \& M.E. Gordon (1993). Direct Mail Privacy-Efficiency Tradeoffs Within an Implied Social Contract Framework. Journal of Public Policy and Marketing, 12(2), 206-215.

Nelson, P.J. (1970). Information and Consumer Behaviour. Journal of Political Economy, 78(2), 311-329.

OECD (2000). Consumers' Internet Purchases by Product. Paris: OECD.

Pavitt, D. (1997). Retailing and the High Street. International Journal of Retail and Distribution Management, 25(1), 38-43.

Phelps, E.S. (ed.) (1975). Altruism, Morality and Economic Theory. New York: Russell Sage.

Price, L.J. \& N. Dawar (2002). The Joint Effects of Brands and Warranties in Signaling New Product Quality. Journal of Economic Psychology, 23, 165-190.

Reed, S. (1999). Online Shopping? You Bet! InfoWorld, 21(43), 91.

Rosen, K. \& A. Howard (2000). E-Retail: Gold Rush or Fool's Gold? California Management Review, 42 (3), 72-100.

Rothschild, M. \& J. Stiglitz (1976). Equilibrium in Competitive Insurance Markets: An Essay on the Economics of Imperfect Information. Quarterly Journal of Economics, 90(4), 629-649.

Rousseau, D.M., S.B. Sitkin, R.S. Burt \& C. Camerer (1998). Not So Different After All: A Cross-Discipline View of Trust. Academy of Management Review, 23(3), 393-404.

Sheehan, K.B. \& M.G. Hoy (2000). Dimensions of Privacy Concern Among Online Consumers. Journal of Public Policy and Marketing, 19(1), 62-73. 
Sherif, C., M. Sherif \& R.E. Nebergall, (1965). Attitude and Attitude Change, Philadelphia: W.B. Saunders.

Shern, S. \& F. Crawford (1999). The Second Annual Internet Shopping Study. Ernst \& Young.

Sinha, I. (2000). Cost Transparency: The Net's Real Threat to Prices and Brands. Harvard Business Review, March-April, 43-50.

Spence, A.M. (1973). Job Market Signalling. Quarterly Journal of Economics, 87 (3), $355-374$.

Spence, A.M. (1974). Market Signaling: Informational Transfer in Hiring and Related Screening Processes, Harvard University Press.

Spiekermann, S., J. Grossklags \& B. Berendt (2001). E-privacy in 2nd Generation Ecommerce: Privacy Preferences Versus Actual Behavior. Proceedings of the 3rd ACM Conference on Electronic Commerce, Tampa, Florida, 38-47.

Stewart, K.J. (1999). Transference as a Means of Building Trust in World Wide Web Sites. In Proceedings of the Twentieth International Conference on Information Systems, Charlotte, NC, December, 459-464.

Stiglitz, J.E. \& A. Weiss (1981). Credit Rationing in Markets with Imperfect Information. American Economic Review, 71(3), 393-410.

Swait, J., T. Erdem, J. Louviere \& C. Dubelaar (1993). The Equalization Price: A Measure of Consumer-perceived Brand Equity. International Journal of Research in Marketing Vol 10, March, 23-45.

Tan, S.J. (1999). Strategies for Reducing Consumers' Risk Aversion in Internet Shopping. Journal of Consumer Marketing, 16(2), 163-180.

Wiener, J.L. (1985). Are Warranties Accurate Signals of Product Reliability? Journal of Consumer Research, 12(2), 245-250. 
Zeithaml, V.A. (1988). Consumer Perceptions of Price, Quality, and Value: A MeansEnds Model and Synthesis of Evidence. Journal of Marketing, 52(3), 2-22. 
TABLE 1: Utility Coefficients from NLogit Estimation*

\begin{tabular}{|c|c|c|c|c|c|c|}
\hline \multicolumn{2}{|c|}{ McFadden's Rho } & Full Model & Shoes & Watches & Computers & Jeans \\
\hline \multicolumn{2}{|c|}{ Squared $\Rightarrow$} & $\mathrm{R}^{2}=0.159$ & $\mathrm{R}^{2}=0.176$ & $\mathrm{R}^{2}=0.184$ & $\mathrm{R}^{2}=0.175$ & $\mathrm{R}^{2}=0.159$ \\
\hline \multicolumn{2}{|l|}{ Variable } & Coefficient & Coefficient & Coefficient & Coefficient & Coefficient \\
\hline \multirow{2}{*}{\multicolumn{2}{|c|}{ ASC_STORE }} & 0.0430 & 0.0316 & 0.2034 & -0.2111 & 0.0700 \\
\hline & & 0.1651 & 0.6235 & 0.0005 & 0.0028 & 0.2300 \\
\hline \multicolumn{2}{|c|}{ ASC_WWW } & -0.5160 & -0.7437 & -0.4131 & -0.4009 & -0.5585 \\
\hline \multirow{9}{*}{ STORE } & \multirow{3}{*}{ BRAND } & 0.0000 & 0.0000 & 0.0000 & 0.0000 & 0.0000 \\
\hline & & 0.4646 & 0.5421 & 0.4273 & 0.4897 & 0.4366 \\
\hline & & 0.0000 & 0.0000 & 0.0000 & 0.0000 & 0.0000 \\
\hline & \multirow[t]{2}{*}{ MBG } & 0.3866 & 0.3196 & 0.4750 & 0.4683 & 0.3032 \\
\hline & & 0.0000 & 0.0000 & 0.0000 & 0.0000 & 0.0000 \\
\hline & \multirow[t]{2}{*}{ DELIVERY } & 0.4079 & 0.4586 & 0.3567 & 0.4944 & 0.3710 \\
\hline & & 0.0000 & 0.0000 & 0.0000 & 0.0000 & 0.0000 \\
\hline & \multirow[t]{2}{*}{ PRICE } & 0.5296 & 0.5092 & 0.5343 & 0.5007 & $\mathbf{0 . 5 3 3 0}$ \\
\hline & & 0.0000 & 0.0000 & 0.0000 & 0.0000 & 0.0000 \\
\hline \multirow{10}{*}{ WWW } & \multirow[t]{2}{*}{ BRAND } & 0.5446 & 0.5804 & 0.4933 & 0.6111 & 0.4771 \\
\hline & & 0.0000 & 0.0000 & 0.0000 & 0.0000 & 0.0000 \\
\hline & \multirow[t]{2}{*}{ MBG } & 0.4872 & 0.4544 & 0.4813 & 0.5995 & 0.4412 \\
\hline & & 0.0000 & 0.0000 & 0.0000 & 0.0000 & 0.0000 \\
\hline & \multirow[t]{2}{*}{ DELIVERY } & 0.2730 & 0.2781 & 0.2602 & 0.4123 & 0.1760 \\
\hline & & 0.0000 & 0.0001 & 0.0000 & 0.0000 & 0.0032 \\
\hline & \multirow[t]{2}{*}{ PRICE } & 0.5003 & 0.5850 & 0.5611 & 0.3886 & 0.4787 \\
\hline & & 0.0000 & 0.0000 & 0.0000 & 0.0000 & 0.0000 \\
\hline & \multirow[t]{2}{*}{ PRIVACY } & 0.4837 & 0.4589 & 0.6199 & 0.4162 & 0.4381 \\
\hline & & 0.0000 & 0.0000 & 0.0000 & 0.0000 & 0.0000 \\
\hline
\end{tabular}

* $p$ values are reported below the coefficients; coefficients not significant at the $\mathrm{p}<0.05$ level have been greyed. 